\title{
Long-term effects of the SLC2A9 G844A and SLC22A12 C246T variants on serum uric acid concentrations in children
}

\author{
Hye Ah Lee ${ }^{1,2}$, Bo Hyun Park', Eun Ae Park ${ }^{3}$ Su Jin Cho ${ }^{3}$, Hae Soon Kim³ and Hyesook Park ${ }^{1 *}$
}

\begin{abstract}
Background: We evaluated the effects of two single-nucleotide polymorphisms on UA concentrations in the first decade of life using repeated-measures data.

Methods: We included all subjects who were followed-up at least once and for whom we had both UA and genotypic data (i.e., 375, 204, 307, and 363 patients aged 3, 5, 7, and 9 years, respectively). All participated in the Ewha Birth and Growth Cohort study. We used a mixed model analysis to estimate the longitudinal association of serum UA concentration due to the rs3825017 (SLC22A12 C. 246C > T) and rs16890979 (SLC2A9 c. 844G > A) genotypes.

Results: Overall, the tracking coefficient of UA concentrations in children 3 to 9 years of age was 0.31 , and was higher in boys than in girls $(0.34$ vs. 0.29 , respectively). Regarding individual variance, serum UA concentrations decreased as age increased $(\beta=-0.07, p<0.05)$, but there were no significant differences by sex. The effects of rs3825017 on UA concentration were significant in boys, but not in girls. Boys with the T allele of rs3825017 had higher concentrations than their counterparts regardless of the time of follow-up. The rs16890979 genotypes were not significantly associated with serum UA concentration in either sex.
\end{abstract}

Conclusion: This study showed that rs3825017 in the SLC22A12 gene was associated with UA concentration in childhood.

Keywords: Children, Longitudinal study, Urate transporter 1, Uric acid

\section{Background}

Uric acid (UA) is the major endpoint of purine metabolism in humans $[1,2]$. Serum UA concentration is modulated by urate excretion and reabsorption, which mainly occurs in the kidneys [1, 2]. An abnormally high serum concentration of UA is a predictor of vascular disease, gout, and renal disease [1], and is also associated with pediatric hypertension [3]. In addition, a longitudinal cohort study of the Bogalusa Heart Study reported that UA concentration in childhood is a significant predictor of blood pressure later in life [4].

It has been suggested that genetic variants markedly contribute to UA concentrations [5], with an estimated heritability of $-70 \%$ [6]. Genome-wide association (GWA)

\footnotetext{
* Correspondence: hpark@ewha.ac.kr

'Department of Preventive Medicine, College of Medicine, Ewha Womans University, 1071, Anyangcheon-ro, Yangcheon-ku, Seoul 158-710, Korea Full list of author information is available at the end of the article
}

studies of common variants identified more than 30 genetic loci associated with the UA concentrations, mostly in urate transporters, such as the genes encoding solute carrier family 2 facilitated glucose transporter member 9 (also known as SLC2A9 encoding GLUT9), solute carrier family 22 (organic anion/cation transporter) member 12 (also known as SLC22A12 encoding URAT1), and the ATP-binding cassette transporter subfamily G member 2 (ABCG2) $[2,5]$. The importance of URAT1 and GLUT9 for regulating blood urate levels was confirmed, and mutations in SLC22A12 and SLC2A9 have been reported to be responsible for hypouricemia [7]. $A B C G 2$ is also known to be a major cause of gout and hyperuricemia that acts by decreasing urate excretion [8]. Among these candidate genes, the missense single-nucleotide polymorphisms (SNPs) rs3733591 (c. 881G > A) and rs16890979 (c. 844G > A) in the $S L C 2 A 9$ gene had significant effects on gout in an Asian population [9]. Both polymorphisms protected against the

(c) The Author(s). 2018 Open Access This article is distributed under the terms of the Creative Commons Attribution 4.0 International License (http://creativecommons.org/licenses/by/4.0/), which permits unrestricted use, distribution, and 
development of gout, and rs16890979 showed a stronger association than rs3733591 [9]. The protective effect of common variant p.V12 M (rs2231137) in ABCG2 on gout was also reported in a meta-analysis (odds ratio $=0.73$, $p<0.0001$ ) [10], but the functional characterization of this variant did not show altered urate transport activity [11]. As variants in SLC22A12 related to hypouricemia, c.774G > A and c.269G > A were identified in Japanese [12] and Korean [13] subjects, and c.1245_1253del and c.1400C $>\mathrm{T}$ were found in the Roma population [14]. In addition, a recent study of Korean men reported five tagging SNPs of URAT1, of which rs3825017 (c. 246C > T) showed a strong association with hyperuricemia despite the small sample size [15]. Except for genetic effects, birth weight [16], dietary intake [1, 17], and body mass index (BMI) [18] are also correlated with UA concentrations.

Evidence from GWA and epidemiology studies has suggested a number of candidate genes and a recent study from the Viva La Familia Study also reported genetic variants in SLC2A9 associated with UA concentrations in children [19]. Studies evaluating the effects of gene variants in the context of controlling UA concentrations are important, but insufficient research has been conducted in children. On reviewing the literature and considering the possibility of genotype analysis, we assessed the effects of two SNPs (rs3825017 genotype of SLC22A12 and rs16890979 genotype of $S L C 2 A 9$ ) of UA-related genes on the UA concentration in childhood using repeated-measures UA data derived from the Ewha Birth \& Growth Cohort study to determine whether genetic variants influence the UA concentrations during the first 10 years of life. Because there is little data on how the UA concentration is maintained over time, we also estimated the tracking coefficient of the UA concentrations during childhood.

\section{Methods}

\section{Study subjects}

This study was conducted as part of the ongoing Ewha Birth \& Growth Cohort study, a single-hospital-based prospective cohort that was established in 2001-2006. The cohort was started to investigate the risk and preventive factors that may be associated with growth and disease susceptibility via longitudinal observations. The study enrolled 940 subjects at 24-28 weeks pregnancy who visited Ewha Womans University Mokdong Hospital, Seoul, Korea for prenatal care. We conducted follow-up when their offspring reached the ages of 3, 5, and 7 years and annually thereafter. By 2016, the follow-up of children aged 9 years had been completed. The methodology of the cohort study has been reported elsewhere [20, 21]. In this study, two SNPs were genotyped in the subjects who were followed up at least once. There were 471, 400, 364, and 400 cohort members who were followed up at the ages of $3,5,7$, and 9 years, respectively. Of these, we included subjects who had both UA and genotype data (i.e., 375, 204, 307, and 363 at ages 3, 5, 7, and 9 years, respectively). This study was composed of 620 children because many children attended multiple follow-up visits. Written informed consent for participation in the study was obtained from the parents or guardians of all of the study participants at the time of follow-up. The study protocol was approved by the Institutional Review Board of Ewha Womans University Hospital (approval No. EUMC 2015-04-048). All processes were performed in accordance with relevant guidelines and regulations.

\section{Uric acid measurements}

When visiting a hospital to participate in the follow-up program, we collected a blood sample from an antecubital vein in a vacutainer tube containing ethylenediaminetetraacetic acid (EDTA). All blood sample were obtained after fasting at least $8 \mathrm{~h}$. Serum UA concentrations were measured using the uricase-peroxidase coupled reaction method on a Hitachi Auto-analyzer 7600 (Hitachi, Fukuoka, Japan) in the Clinical Biochemistry Department of the Seegene Medical Foundation, Seoul, Korea. UA measurements during follow-up were performed in the same way.

\section{Genotyping the two SNPs}

The genotypes of rs3825017 in SLC22A12 and rs16890979 in $S L C 2 A 9$ were screened using the TaqMan fluorogenic $5^{\prime}$ nuclease assay (ABI, Foster City, CA, USA). The final volume of the polymerase chain reaction (PCR) was $5 \mu \mathrm{L}$, and each reaction contained $10 \mathrm{ng}$ genomic DNA, $2.5 \mu \mathrm{L}$ TaqMan Universal PCR Master Mix, and $0.13 \mu \mathrm{L} 20 \times$ Assay Mix. The thermal cycle conditions were as follows: $50{ }^{\circ} \mathrm{C}$ for 2 min to activate the uracil $\mathrm{N}$-glycosylase and to prevent carry-over contamination, $95^{\circ} \mathrm{C}$ for $10 \mathrm{~min}$ to activate the DNA polymerase, followed by 45 cycles at $95^{\circ} \mathrm{C}$ for $15 \mathrm{~s}$ and $60^{\circ} \mathrm{C}$ for $1 \mathrm{~min}$. All of the PCR reactions were performed using 384-well plates on a Dual 384-Well GeneAmp PCR System 9700 (ABI). The endpoint fluorescent readings were performed on an ABI PRISM $7900 \mathrm{HT}$ Sequence Detection System (ABI). Duplicate samples and negative controls were included to ensure the accuracy of genotyping, which was performed at DNA Link Inc. in Seoul, Korea. The distribution of the two SNPs in the study subjects satisfied Hardy-Weinberg equilibrium.

\section{Covariates}

As covariates, we considered BMI and birth weight, based on previous studies $[16,18]$. Maternal education level was used as a measure of socioeconomic status because it changes little over time (graduated from high school or some college or higher). Anthropometric data were collected by trained researchers when the subjects visited the hospital to participate in the follow-up program. Height 
and weight were measured to the nearest $0.1 \mathrm{~cm}$ and $0.1 \mathrm{~kg}$, respectively, while wearing light clothing and no shoes using a stadiometer and calibrated scale. BMI was calculated as weight $(\mathrm{kg}) /$ height $^{2}\left(\mathrm{~m}^{2}\right)$. BMI at each follow-up point was considered a covariate. Birth weight was obtained from the hospital birth records.

\section{Statistical analysis}

Numerical variables are presented as the mean and standard deviation and categorical variables were presented as the number of subjects and percent. Using repeated-measures data for UA concentrations in subjects aged 3, 5, 7, and 9 years, we estimated the intra-class correlation (ICC) as the tracking coefficient through mixed model analysis [22]. There was no critical tracking value. We interpreted < 0.3 as weak, $0.3-0.6$ as moderate, and $>0.6$ as strong, based on a previous study [23]. The average difference in UA concentration by sex was evaluated using Student's $t$-test. The average UA concentration according to genotype was analyzed using a generalized linear model.

To investigate the long-lasting effects of genetic variants on UA concentration, we used mixed model analysis with a random intercept model. Analyses were conducted using a variance component structure based on lower Akaike information criterion (AIC) values for model selection. The genetic variant used a dominant model ( $\mathrm{CC}$ vs. $\mathrm{CT}+\mathrm{TT}$ genotypes) to ensure that the groups had sufficient subjects. Maternal education level and birth weight were treated as time-independent covariates. The BMI at each follow-up visit was considered a time-dependent covariate. To assess the effect modifier, we also included the interaction between sex and genotype as a dominant model.

All of the statistical tests were conducted using SAS 9.4 (SAS Institute, Cary, NC, USA) with two-sided tests, and a $p$ value $<0.05$ was considered statistically significant. For the interaction, $P$ values $<0.1$ were considered to be significant, based on a previous report [24].

\section{Results}

Two SNPs were examined in 620 children. The rs3825017 allele frequencies of $\mathrm{CC}, \mathrm{CT}$, and TT were $61.1 \%, 34.9 \%$, and 4.0\%, respectively. The rs16890979 allele frequencies of GG, GA, and AA were $99.0 \%, 1.0 \%$, and $0.0 \%$, respectively (Table 1). The genetic polymorphism distribution did not differ by sex $\left(p>0.05, \chi^{2}\right.$ test $)$ and there was no sex difference in UA concentration with follow-up time $(P>0.05)$. Overall, the tracking coefficient of UA concentration from 3 to 9 years of age was 0.31 , and was higher in boys than in girls ( 0.34 vs. 0.29 , respectively). While the tracking coefficient of UA concentration from 5 to 9 years of age was higher (total $=0.37$, boys $=0.39$, girls $=0.34$ ), these values can interpreted as showing moderate stability.
Table 2 shows the average UA concentration for genetic models of the two polymorphisms. There was a limited ability to assess the effects of rs16890979 on UA concentration because the minor allele frequency was very low. Thus, its result was not presented in the table. The effects of rs3825017 on UA concentration were significant in boys, but not in girls. Boys with the $\mathrm{T}$ allele of rs3825017 had higher concentrations than their counterparts at baseline (Table 2). In boys, carriers with one or two $\mathrm{T}$ alleles (i.e., CT or TT) had a higher mean UA concentration than non-carriers regardless of the time of follow-up, even after adjusting for birth weight, maternal education level, time, and BMI at each follow-up point. In girls, no effects of rs3825017 on UA concentration were apparent (Fig. 1).

The longitudinal effects of rs3825017 genotype on individual UA concentration are presented in Table 3. The random intercept model showed that UA concentration at baseline varied among the children. When estimating changes in UA concentration with age, we found that concentration decreased by $4.39 \mu \mathrm{mol} / \mathrm{L}$ with every 2 -year increase in age $(P<0.001)$. Individual UA concentrations changed at the same rate with age in the children, indicating that there were no significant effects of a random slope in time. The rs3825017 genotypes had significant effects on the changes in UA concentration in the first decade of life in boys only (Table 3 ). The effect of BMI on the UA concentrations was not significant in either sex. Maternal education level as a measure of socioeconomic status and birth weight had no effect on UA concentration. After adjusting for the interaction between genotypes and sex, the difference in sex was significant $(P$ for interaction $=0.08)$. The longitudinal effects of rs16890979 were not assessed due to the very low frequency of the minor allele.

\section{Discussion}

This study used a longitudinal approach to examine the relationship between two candidate SNPs and UA concentration in a general pediatric population. The rs3825017 genotype of SLC22A12 had a notable effect on UA concentration in the first 10 years of life in boys. Although there was no sex difference in UA concentration, the genetic effects of rs3825017 on concentration differed by sex $(P$ genotype $\times$ sex $=0.08)$ during childhood. The tracking coefficient of UA from 3 to 9 years of age showed moderate stability.

Both SLC22A12, which encodes urate transporter 1 (URAT1), and SLC2A9, which encodes glucose transporter 9 (GLUT9), are involved in modulating urate reabsorption in the renal tubules. A meta-analysis of GWA studies identified multiple candidate loci related to UA level in European (SLC2A9, ABCG2, SLC17A1, SLC22A11, SLC22A12, SLC16A9, GCKR, LRRC16A, and PDZK1) and East Asian (SLC2A9, ABCG2, SLC22A12, 
Table 1 Distribution of SLC2A9 G844A and SLC22A12 C246T variants and characteristics of the study subjects

\begin{tabular}{|c|c|c|c|}
\hline & \multicolumn{3}{|c|}{ Unit: $n(\%)$ or mean (standard deviation) } \\
\hline & Total & Boys & Girls \\
\hline \multicolumn{4}{|l|}{ Genetic variants } \\
\hline \multicolumn{4}{|l|}{ rs3825017 polymorphism } \\
\hline CC & $377(61.1 \%)$ & $197(62.5 \%)$ & $180(59.6 \%)$ \\
\hline CT & $215(34.9 \%)$ & $107(34.0 \%)$ & $108(35.8 \%)$ \\
\hline$\pi$ & $25(4.0 \%)$ & $11(3.5 \%)$ & $14(4.6 \%)$ \\
\hline \multicolumn{4}{|l|}{ rs16890979 polymorphism } \\
\hline GG & $614(99.0 \%)$ & $312(98.7 \%)$ & $302(99.3 \%)$ \\
\hline GA & $6(1.0 \%)$ & $4(1.3 \%)$ & $2(0.7 \%)$ \\
\hline \multicolumn{4}{|c|}{ Serum uric acid concentration ( $\mu \mathrm{mol} / \mathrm{L})$ at each FU age } \\
\hline UA at 3 years of age & $223.44(46.44)$ & $225.38(43.98)$ & $221.52(48.78)$ \\
\hline UA at 5 years of age & $235.94(42.55)$ & $234.60(41.55)$ & $237.28(43.69)$ \\
\hline UA at 7 years of age & $223.97(55.64)$ & $219.92(57.03)$ & $227.94(54.12)$ \\
\hline UA at 9 years of age & $211.59(48.85)$ & $214.19(52.04)$ & $208.97(45.41)$ \\
\hline \multicolumn{4}{|l|}{ Covariates } \\
\hline Birth weight (kg) & $3.09(0.59)$ & $3.15(0.59)$ & $3.03(0.58)$ \\
\hline BMI $\left(\mathrm{kg} / \mathrm{m}^{2}\right)$ at 3 years of age & $15.47(1.31)$ & $15.49(1.33)$ & $15.45(1.29)$ \\
\hline $\mathrm{BMI}\left(\mathrm{kg} / \mathrm{m}^{2}\right)$ at 5 years of age & $15.71(1.67)$ & $15.94(1.78)$ & $15.47(1.53)$ \\
\hline BMI $\left(\mathrm{kg} / \mathrm{m}^{2}\right)$ at 7 years of age & $15.95(2.10)$ & $16.19(2.18)$ & $15.72(2.01)$ \\
\hline BMI $\left(\mathrm{kg} / \mathrm{m}^{2}\right)$ at 9 years of age & $17.50(2.58)$ & $17.88(2.75)$ & $17.14(2.35)$ \\
\hline \multicolumn{4}{|l|}{ Maternal education level } \\
\hline Graduated from high school & $132(22.2 \%)$ & $64(21.2 \%)$ & $68(23.3 \%)$ \\
\hline Some college or higher & $462(77.8 \%)$ & $238(78.8 \%)$ & $224(76.7 \%)$ \\
\hline
\end{tabular}

UA uric acid, FU follow-up, BMI body mass index

and $M A F)$ populations $[2,25]$. Mutations in $S L C 22 A 12$ or $S L C 2 A 9$ were initially reported in Japanese patients with renal hypouricemia, although patients from various ethnic groups have subsequently been identified [7]. A study of children in the Viva La Familia Study also recently showed that the serum UA concentration was associated strongly with genetic variants in SLC2A9 through GWA analysis [19]. Of genetic variants, the Hereditary and Phenotype Intervention (HAPI) Heart Study found that rs16890979 in SLC2A9 was associated

Table 2 Baseline differences in the uric acid concentrations ( $\mu \mathrm{mol} / \mathrm{L}$ ) for each genetic model ${ }^{\mathrm{a}}$

\begin{tabular}{|c|c|c|c|c|c|c|c|c|c|c|c|c|}
\hline & \multicolumn{4}{|c|}{ Total } & \multicolumn{4}{|c|}{ Boys } & \multicolumn{4}{|l|}{ Girls } \\
\hline & $n$ & Mean & S.D. & $p$ & $n$ & Mean & S.D. & p & $n$ & Mean & S.D. & $p$ \\
\hline \multicolumn{13}{|c|}{ Dominant model for rs3825017 } \\
\hline $\mathrm{CC}$ & 222 & 221.58 & 47.98 & 0.37 & 112 & 219.17 & 45.44 & 0.02 & 110 & 224.02 & 50.52 & 0.40 \\
\hline$C T+\pi$ & 151 & 226.02 & 44.40 & & 73 & 234.66 & 40.44 & & 78 & 217.94 & 46.64 & \\
\hline \multicolumn{13}{|c|}{ Recessive model for rs3825017 } \\
\hline$C C+C T$ & 355 & 223.19 & 46.79 & 0.73 & 178 & 224.02 & 43.97 & 0.05 & 177 & 222.36 & 49.57 & 0.33 \\
\hline$\pi$ & 18 & 227.02 & 42.81 & & 7 & 257.46 & 36.13 & & 11 & 207.64 & 35.63 & \\
\hline \multicolumn{13}{|c|}{ Codominant model for rs3825017 } \\
\hline $\mathrm{CC}$ & 222 & 221.58 & 47.98 & 0.66 & 112 & 219.17 & 45.44 & 0.02 & 110 & 224.02 & 50.52 & 0.53 \\
\hline CT & 133 & 225.89 & 44.77 & & 66 & 232.24 & 40.36 & & 67 & 219.63 & 48.21 & \\
\hline$\pi$ & 18 & 227.02 & 42.81 & & 7 & 257.46 & 36.13 & & 11 & 207.64 & 35.63 & \\
\hline
\end{tabular}

$S . D$ standard deviation

${ }^{a}$ For the baseline differences, the results were obtained using the uric acid concentrations at 3 years of age 


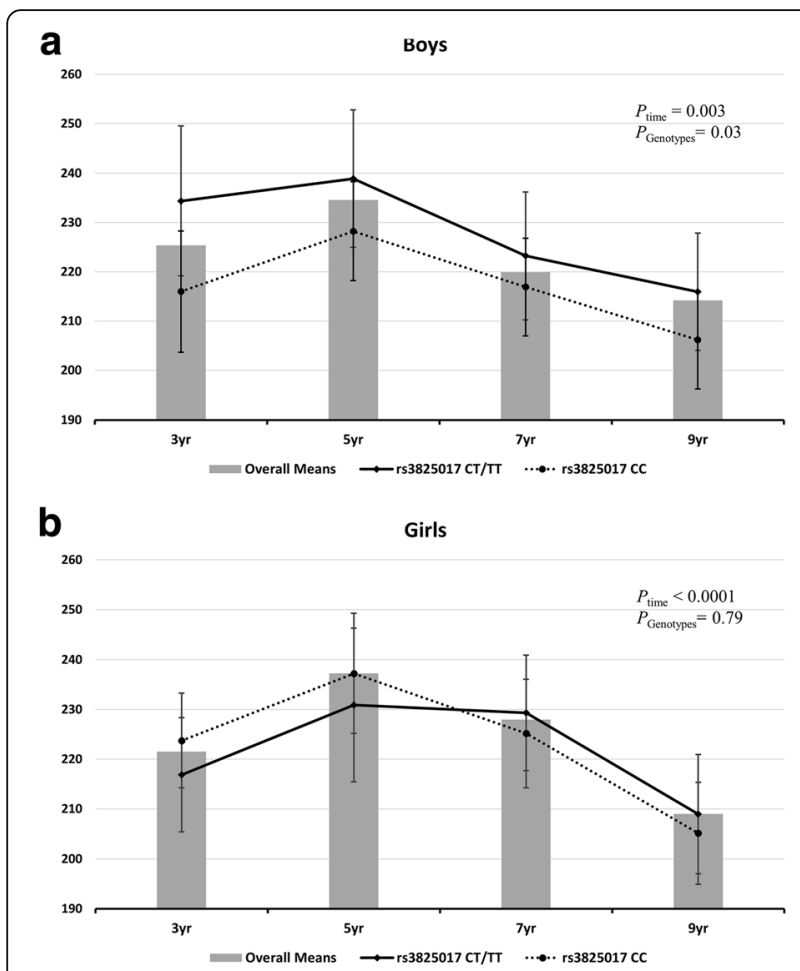

Fig. 1 The average uric acid concentrations ( $\mu \mathrm{mol} / \mathrm{L}$ ) with the dominant model of rs3825017 genotypes from 3 to 9 years of age, by sex. a Boys, b Girls The least-squared mean by genotypes (as a dominant model) at each follow-up age were obtained from a mixed model under a random intercept model with variance components structure. It was estimated while controlling for time, birth weight, maternal education level, and body mass index at each time point. Genetic variants and time were applied as categorical values to obtain the mean values for the genetic variant at each time point. The box indicates the average UA concentration, and the vertical lines show the standard error

with UA concentrations and it accounted for $4.3 \%$ of the variance [26]. This association was also reported in studies of the Framingham and Rotterdam cohorts [5] and a Czech population [27], but there was a discrepancy in the direction of association. This might involve additional factors, such as diet, lifestyle, and different linkage disequilibrium structures $[8,27]$. Although two meta-analyses reported that the dominant model of rs16890979 was associated with gout in an Asian population [9, 28], our study had limited statistical strength due to the low minor allele frequency; the minor allele frequency of rs16890979 was less than 0.02 in the populations of China and Japan, was greater than 0.29 in a European population [29], 0.23 in the Framingham Heart Study, and was 0.21 in the Rotterdam Study [5]. In addition, SLC2A9 rs16890979 showed possible associations with gout [9] and hyperuricemia [30]. However, functional characterization of SLC2A9 rs16890979 in an experimental validation study revealed no significant difference in the expression of GLUT9 [30]. Functional studies are likely to be important in determining the causality of disease-related SNPs.

In our study, rs3825017 in SLC22A12 affected UA concentration in boys, but not in girls. Three other studies have examined rs3825017 [12, 15, 31]. In line with our study, one study of Korean men found an association with hyperuricemia (odds ratio $=2.29,95 \%$ confidence interval 1.78 to 2.93), while studies from Japanese and Chinese population found no significant effect. The latter studies did not assess sex differences, which needs further study. Regarding to $S L C 2 A 9$, several studies have suggested sex differences by genotype including rs16890979; the effects were seen more clearly in women than in men [2,32]. The sex difference can be explained by sex hormones. Because estrogen is uricosuric [33], the differences with the rs3825017 genotype are expected to be more distinct around puberty. A recent GWA study of gout and its subtypes revealed that HIST1H2BF-HIST1H4E, NIPAL1, and FAM35A were novel risk loci [8]. However, detailed knowledge of the functional pathways of these genes affecting UA concentrations remains limited and further studies are required.

Although the pathological mechanism of UA is unclear, Mazzali et al. reported that rats with induced mild hyperuricemia develop mild hypertension and slightly reduced renal function [34]. In addition, injury was seen in the afferent arterioles of the renal microvasculature in the hyperuricemic rat $[35,36]$. These experimental studies also suggested that these

Table 3 Longitudinal effects of rs3825017 genotypes on individual serum uric acid concentrations

\begin{tabular}{|c|c|c|c|c|c|c|c|c|c|}
\hline & \multicolumn{3}{|l|}{ Total } & \multicolumn{3}{|l|}{ Boys } & \multicolumn{3}{|l|}{ Girls } \\
\hline & $\bar{\beta}$ & S.E. & $p$ & $\bar{\beta}$ & S.E. & $p$ & $\bar{\beta}$ & S.E. & $p$ \\
\hline Sex & 0.48 & 3.37 & 0.89 & - & & & - & & \\
\hline FU time & -4.39 & 1.18 & $<0.001$ & -4.51 & 1.71 & $<0.01$ & -4.06 & 1.65 & 0.01 \\
\hline Dominant model for rs3825017 & 5.13 & 3.44 & 0.14 & 11.98 & 4.94 & 0.02 & -0.88 & 4.77 & 0.85 \\
\hline BMI & 1.47 & 0.76 & 0.05 & 1.90 & 1.02 & 0.06 & 0.92 & 1.16 & 0.43 \\
\hline Birth weight & -1.50 & 2.92 & 0.61 & 2.57 & 4.08 & 0.53 & -4.79 & 4.20 & 0.25 \\
\hline Maternal education & 5.46 & 4.02 & 0.17 & 8.95 & 5.76 & 0.12 & 3.09 & 5.61 & 0.58 \\
\hline
\end{tabular}

FU follow-up, $B M I$ body mass index

The rs3825017 genotypes for the dominant model ( $C C$ and $C T+T T$ )

The coefficients $(\beta)$ were obtained from a mixed model under random intercept model with variance components structure 
changes could be prevented by maintaining UA concentration in the normal range [1,34,35].

Even in children, UA had an independent effect on higher blood pressure after controlling for adiposity factors, renal function, and pubertal status [18]. A cohort study with an average 12-year follow-up also reported that the UA concentration in childhood and changes in concentration were significant predictors of blood pressure in later life [4]. Feig et al. suggested that serum UA concentration is directly correlated with blood pressure, and that hyperuricemia showed a stronger association in childhood primary hypertension than in secondary or white-coat hypertension [3]. Therefore, control of UA levels may be important to prevent disease. In our study, the tracking coefficient of UA during the 6-year follow-up period beginning at 3 years of age showed moderate stability $(\mathrm{ICC}=0.31)$. The tracking coefficient of UA from 5 to 9 years of age was slightly higher $(\mathrm{ICC}=0.37)$. The UA concentration in blood can vary with age, sex, and pubertal status $[4,19]$. Unlike previous studies, we found no differences in UA concentration with sex, and the average UA concentration decreased with increasing age during the first decade of life. Our study examined younger subjects than those used in previous studies [4, 18,37], and there are few prospective studies of UA using repeated measures. Thus, it is difficult to explain the difference.

To the best of our knowledge, this is the first study to assess the persistent effects of genetic variants on the UA concentration during childhood. Compared with non-carriers, boys with carriers of at least one rs $3825017 \mathrm{~T}$ allele exhibited elevated UA concentrations. Our results support those of an earlier study conducted in Korean males [15]. Additionally, BMI was positively associated with the UA concentration during childhood, with borderline significance in boys but not in girls.

This study had several weaknesses. First, we assessed the effect of one tag SNP; other genetic variants near URAT1 may also be important. In addition, residual confounding by unmeasured factors may affect UA concentration. Conversely, our results are less likely to be influenced by unhealthy factors such as alcohol consumption and comorbidities compared to adult studies and case-control studies, because this study examined a general pediatric population. We assumed that the genetic variants were dichotomized by a dominant effect of the risk allele due to the low frequency of homozygous carriers of the risk allele. It is necessary to confirm this in a large-scale study and in studies of different ethnic groups. To verify the statistical power, we calculated the required sample size for linear mixed model with random intercept. As a result, 41 subjects per group were required to evaluate the significance of a difference in the UA concentration between the two groups (non-carriers vs carriers of at least one $\operatorname{rs} 3825017 \mathrm{~T}$ allele), assuming that the power was $80 \%$ with $\alpha=0.05$, four repeated measurements, and mean difference-11.3. Thus, we found that the statistical power of our study was adequate. Finally, there is a limit to generalizing our findings because the evidence is still insufficient.

\section{Conclusions}

In summary, we estimated the stability of UA concentration over 6 years beginning in early childhood, and observed moderate stability. A single measurement of UA during childhood may have a limited ability to predict disease in later life. Through a longitudinal approach, we also found that rs3825017 genotype had a notable effect on UA concentration in boys during childhood. Our study considered only two SNPs (rs3825017 in SLC22A12 and rs16890979 in SLC2A9). Therefore, further studies with extended follow-up periods are required to consider other major genetic loci associated with UA concentrations, such as glucokinase regulatory protein $(G C K R)$ and ABCG2 [2].

\section{Abbreviations}

ABCG: ATP-binding cassette transporter; AIC: Akaike information criterion; BMl: Body mass index; EDTA: Ethylenediaminetetraacetic acid; GCKR: Glucokinase regulatory protein; GLUT9: Glucose transporter 9; GWA: Genome-wide association; ICC: Intra-class correlation; PCR: Polymerase chain reaction; SLC22A12: Solute carrier family 22 (organic anion/cation transporter) member 12; SLC2A9: Solute carrier family 2 facilitated glucose transporter member 9; SNP: Single-nucleotide polymorphism; UA: Uric acid; URAT1: Urate transporter 1

\section{Funding}

This research was supported by the Basic Science Research Program through the National Research Foundation of Korea (NRF), funded by the Ministry of Science, ICT\& Future Planning (NRF-2014R1A1A3051023).

\section{Availability of data and materials}

All data generated or analysed during this study are included in this published article.

\section{Authors' contributions}

Conceptualization, EAP, SJC, HSK, and HP; formal analysis, HAL; data curation, HAL, BHP, EAP, SJC, HSK, and HP; writing the original draft, HAL; reviewing and editing the manuscript, BHP, EAP, SJC, HSK and HP; supervision, HP; approval of the final manuscript, all authors.

\section{Ethics approval and consent to participate}

Written informed consent for participation in the study was obtained from the parents or guardians of all of the study participants. The study protocol was approved by the Institutional Review Board of Ewha Womans University Hospital (approval No. EUMC 2015-04-048).

\section{Consent for publication}

Not applicable.

\section{Competing interests}

The authors declare that they have no competing interests.

\section{Publisher's Note}

Springer Nature remains neutral with regard to jurisdictional claims in published maps and institutional affiliations.

\section{Author details}

${ }^{1}$ Department of Preventive Medicine, College of Medicine, Ewha Womans University, 1071, Anyangcheon-ro, Yangcheon-ku, Seoul 158-710, Korea. 
${ }^{2}$ Clinical Trial Center, Mokdong Hospital, Ewha Womans University, Seoul, Korea. ${ }^{3}$ Department of Pediatrics, College of Medicine, Ewha Womans University, Seoul, Korea.

Received: 28 January 2018 Accepted: 30 August 2018

Published online: 06 September 2018

\section{References}

1. Kutzing MK, Firestein BL. Altered uric acid levels and disease states. J Pharmacol Exp Ther. 2008;324(1):1-7.

2. Kolz M, Johnson T, Sanna S, Teumer A, Vitart V, Perola M, et al. Meta-analysis of 28,141 individuals identifies common variants within five new loci that influence uric acid concentrations. PLoS Genet. 2009;5(6):e1000504.

3. Feig DI, Johnson RJ. The role of uric acid in pediatric hypertension. J Ren Nutr. 2007:17(1):79-83.

4. Alper AB Jr, Chen W, Yau L, Srinivasan SR, Berenson GS, Hamm LL. Childhood uric acid predicts adult blood pressure: the Bogalusa heart study. Hypertension. 2005;45(1):34-8.

5. Dehghan A, Köttgen A, Yang Q, Hwang SJ, Kao WL, Rivadeneira F, et al. Association of three genetic loci with uric acid concentration and risk of gout: a genome-wide association study. Lancet. 2008;372(9654):1953-61.

6. Whitfield JB, Martin NG. Inheritance and alcohol as factors influencing plasma uric acid levels. Acta Genet Med Gemellol. 1983;32:117-26.

7. Claverie-Martin F, Trujillo-Suarez J, Gonzalez-Acosta H, Aparicio C, Justa Roldan ML, Stiburkova B, Ichida K, Martín-Gomez MA, Herrero Goñi M, Carrasco Hidalgo-Barquero M, Iñigo V, Enriquez R, Cordoba-Lanus E, GarciaNieto VM, RenalTube Group. URAT1 and GLUT9 mutations in Spanish patients with renal hypouricemia. Clin Chim Acta. 2018;481:83-9. https://doi. org/10.1016/j.cca.2018.02.030

8. Nakayama A, Nakaoka H, Yamamoto K, Sakiyama M, Shaukat A, Toyoda Y, et al. GWAS of clinically defined gout and subtypes identifies multiple susceptibility loci that include urate transporter genes. Ann Rheum Dis. 2017;76(5):869-77. https://doi.org/10.1136/annrheumdis-2016-209632.

9. Chen Y, Ying Y, Shi S, Li L, Huang Y, Ye H, Gong O, Huang H, Ji H, Huang T, Duan $\mathrm{S}$. A systematic review and meta-analysis of 4 candidate polymorphisms with the risk of gout. Int J Clin Exp Med. 2016;9(8):16025-33.

10. Stiburkova B, Pavelcova K, Zavada J, Petru L, Simek P, Cepek P, Pavlikova M, Matsuo H, Merriman TR, Pavelka K. Functional non-synonymous variants of ABCG2 and gout risk. Rheumatology (Oxford). 2017;56(11):1982-92.

11. Higashino T, Takada T, Nakaoka H, Toyoda Y, Stiburkova B, Miyata H, et al. Multiple common and rare variants of ABCG2 cause gout. RMD Open. 2017; 3(2):e000464.

12. Iwai N, Mino Y, Hosoyamada M, Tago N, Kokubo Y, Endou H. A high prevalence of renal hypouricemia caused by inactive SLC22A12 in Japanese. Kidney Int. 2004;66(3):935-44

13. Lee JH, Choi HJ, Lee BH, Kang HK, Chin HJ, Yoon HJ, Ha IS, Kim S, Choi Y, Cheong HI. Prevalence of hypouricaemia and SLC22A12 mutations in healthy Korean subjects. Nephrology (Carlton). 2008;13(8):661-6. https://doi. org/10.1111/j.1440-1797.2008.01029.x.

14. Gabrikova D, Bernasovska J, Sokolova J, Stiburkova B. High frequency of SLC22A12 variants causing renal hypouricemia 1 in the Czech and Slovak Roma population; simple and rapid detection method by allele-specific polymerase chain reaction. Urolithiasis. 2015;43(5):441-5. https://doi.org/10. 1007/s00240-015-0790-4

15. Cho SK, Kim S, Chung JY, Jee SH. Discovery of URAT1 SNPS and association between serum uric acid levels and URAT1. BMJ Open. 2015;5(11):e009360.

16. Franco MC, Christofalo DM, Sawaya AL, Ajzen SA, Sesso R. Effects of low birth weight in 8- to 13-year-old children: implications in endothelial function and uric acidlevels. Hypertension. 2006:48(1):45-50.

17. Lin WT, Huang HL, Huang MC, Chan TF, Ciou SY, Lee CY, et al. Effects on uric acid, body mass index and blood pressure in adolescents of consuming beverages sweetened with high-fructose corn syrup. Int J Obes (Lond). 2013;37(4):532-9.

18. Viazzi F, Antolini L, Giussani M, Brambilla P, Galbiati S, Mastriani S, et al. Serum uric acid and blood pressure in children at cardiovascular risk. Pediatrics. 2013;132(1):e93-9.

19. Voruganti VS, Laston S, Haack K, Mehta NR, Cole SA, Butte NF, et al. Serum uric acid concentrations and SLC2A9 genetic variation in Hispanic children: the viva La Familia study. Am J Clin Nutr. 2015;101(4):725-32.

20. Lee HA, Park EA, Cho SJ, Kim HS, Kim YJ, Lee H, et al. Mendelian randomization analysis of the effect of maternal homocysteine during pregnancy, as represented by maternal MTHFR C677T genotype, on birth weight. J Epidemiol. 2013;23(5):371-5.

21. Lee HA, Kim YJ, Lee H, Gwak HS, Hong YS, Kim Q, et al. The preventive effect of breast-feeding for longer than 6 months on early pubertal development among children aged 7-9 years in Korea. Public Health Nutr. 2015;18(18):3300-7.

22. Twisk JWR. Applied longitudinal data analysis for epidemiology: a practical guide. Cambridge: Cambridge University Press; 2003. p. 225-7.

23. Pearson N, Salmon J, Campbell K, Crawford D, Timperio A. Tracking of children's body-mass index, television viewing and dietary intake over five-years. Prev Med. 2011:53(4-5):268-70.

24. Prado EL, Maleta K, Ashorn P, Ashorn U, Vosti SA, Sadalaki J, Dewey KG. Effects of maternal and child lipid-based nutrient supplements on infant development: a randomized trial in Malawi. Am J Clin Nutr. 2016;103:784-93.

25. Okada Y, Sim X, Go MJ, Wu JY, Gu D, Takeuchi F, et al. Meta-analysis identifies multiple loci associated with kidney function-related traits in east Asian populations. Nat Genet. 2012:44(8):904-9.

26. Parsa A, Brown E, Weir MR, Fink JC, Shuldiner AR, Mitchell BD, et al. Genotype-based changes in serum uric acid affect blood pressure. Kidney Int. 2012;81(5):502-7.

27. Stibůrková B, Pavlíková M, Sokolová J, Kožich V. Metabolic syndrome, alcohol consumption and genetic factors are associated with serum uric acid concentration. PLoS One. 2014;9(5):e97646. https://doi.org/10.1371/ journal.pone.0097646. eCollection 2014.

28. Meng Q, Yue J, Shang M, Shan Q, Qi J, Mao Z, et al. Correlation of GLUT9 polymorphisms with gout risk. Medicine (Baltimore). 2015;94(44):e1742.

29. Yang B, Mo Z, Wu C, Yang H, Yang X, He Y, et al. A genome-wide association study identifies common variants influencing serum uric acid concentrations in a Chinese population. BMC Med Genomics. 2014;7:10.

30. Hurba O, Mancikova A, Krylov V, Pavlikova M, Pavelka K, Stibůrková B. Complex analysis of urate transporters SLC2A9, SLC22A12 and functional characterization of non-synonymous allelic variants of GLUT9 in the Czech population: no evidence of effect on hyperuricemia and gout. PLoS One. 2014;9(9):e107902

31. Li C, Han L, Levin AM, Song H, Yan S, Wang Y, et al. Multiple single nucleotide polymorphisms in the human urate transporter 1 (hURAT1) gene are associated with hyperuricaemia in Han Chinese. J Med Genet. 2010; 47(3):204-10.

32. McArdle PF, Parsa A, Chang YC, Weir MR, O'Connell JR, Mitchell BD, et al. A common non-synonymous variant in GLUT9 is a determinant of serum uric acid levels in old order Amish. Arthritis Rheum. 2008;58(9):2874-81.

33. Adamopoulos D, Vlassopoulos C, Seitanides B, Contoyiannis P, Vassilopoulos $P$. The relationship of sex steroids to uric acid levels in plasma and urine. Acta Endocrinol. 1977:85(1):198-208.

34. Mazzali M, Kanellis J, Han L, Feng L, Xia Y-Y, Chen Q, et al. Hyperuricemia induces a primary arteriolpathy in rats by a blood pressure-independent mechanism. Am J Physiol Renal Physiol. 2002;6:F991-7.

35. Sánchez-Lozada LG, Tapia E, Avila-Casado C, Soto V, Franco M, Santamaría J, et al. Mild hyperuricemia induces glomerular hypertension in normal rats. Am J Physiol Renal Physiol. 2002;283(5):F1105-10.

36. Watanabe S, Kang DH, Feng L, Nakagawa T, Kanellis J, Lan H, et al. Uric acid, hominoid evolution, and the pathogenesis of salt-sensitivity. Hypertension. 2002;40(3):355-60.

37. Feig DI, Johnson RJ. Hyperuricemia in childhood primary hypertension. Hypertension. 2003:42(3):247-52.

Ready to submit your research? Choose BMC and benefit from

- fast, convenient online submission

- thorough peer review by experienced researchers in your field

- rapid publication on acceptance

- support for research data, including large and complex data types

- gold Open Access which fosters wider collaboration and increased citations

- maximum visibility for your research: over $100 \mathrm{M}$ website views per year

At BMC, research is always in progress.

Learn more biomedcentral.com/submissions 